\title{
Blast Design for Controlling Some of Environmental Nuisances during Deep Hole Blasting in Surface Overburden Benches
}

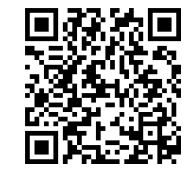

\author{
B S Choudhary* and Anurag Agrawal \\ Department of Mining Engineering, Indian Institute of Technology (ISM) Dhanbad, India
}

Submission: February 12, 2019; Published: September 17, 2019

*Corresponding author: B S Choudhary, Department of Mining Engineering, Indian Institute of Technology (ISM) Dhanbad, India

\begin{abstract}
The present study suggesting a safe methodology to control blast induced ground vibration and air overpressure within the safe limits specifying the safe permissible explosive charge per delay and per round along with the blast design parameters which should be used while blasting mainly to protect vulnerable structures in the vicinity. Keeping in view the above-mentioned requirements, 11 rounds of deep hole trial blasts were studied constituting all together 19 blast events recorded by seismographs. While selecting the blast monitoring stations all the sensitive points have been covered which mainly included, dwellings and structures belonging to owner and a few other places within the mine in order to study the blast induced wave propagation and attenuation for various scaled distance. Safe charges have been recommended after regression analysis and suitable blast patterns were recommended for safe and productive blasting.
\end{abstract}

Keywords : Ground vibration; Fly rock; Air overpressure; Deep hole; Overburden benches

\section{Introduction}

In blasting operation, the local geological conditions must be considered first. Rock competency and fracture patterns have a significant impact on the success of a blasting operation [1]. Due to widely varying nature of rocks, geological structure and explosive materials, blast design parameters are optimized by field testing but monitoring of blast vibrations during actual excavation helps to ensure the safety of the concerned structures as well as to provide necessary data to improve the blasting patterns if required [2]. Venkatesh [3] concluded that the total charge in a blast influences insignificantly on the intensity of the ground vibrations for distances between $100 \mathrm{~m}$ and $3000 \mathrm{~m}$. With the combination of delay detonators and proper blast design, large scale blasts are possible without any significant increase in the vibration levels.

The author Wiss \& Linehan [4] made studies to evaluate the influence of 14 blast variables considered to influence the amplitude of ground vibrations. Monjezi et al. [5] observed from the sensitivity analysis that distance from the site of blast, number of holes per delay and maximum charge per delay are the most influential parameters towards generation of ground vibration in the blasting operation. The ground vibration characteristics depend on maximum charge per delay in any one of the delay intervals instead of total charge used in blast [6]. They found that the charge weight per delay and length of delay to have the most significant influence on ground vibrations. Charge weight per delay is a very important parameter which controls the intensity of ground vibrations. The intensity of vibrations increases as the quantity of charge detonated per delay increases. The selection of a suitable delay interval is extremely important in multi-row blasts. The function of delay detonation is to separate the pressure front into bundles of energy delivered to rock mass to make the events occur in series, independent of breaking. Proper burden relief should be provided to each row for effective movement of the burden rock [7]. If the delay between rows is not enough, the front row burden cannot move forward to enough distance to provide free face to the next subsequent row to move out $[8,9]$. This adds to more confinement of charges in subsequent rows leading to increased ground vibrations and fly rock. It was found that the ground vibration levels could be reduced effectively by arranging delays between rows in such a manner to separate the wave fronts emanating from corresponding charges avoiding the superimposition of waves [10]. Due to higher scattering in Nonel initiation system, it is found that the percentage of seismic energy dissipation during blasting using Nonel initiation system is higher in comparison to blasting using an electronic initiation system. The overlapping of holes leads to improper utilization of explosive energy during 
blasting with Nonel initiation system than an electronic initiation system [11]. Data evaluation is not solely based on peak particle velocities, as it is for conventional methods. Seismic waveforms, their frequency content, and their time-duration are also considered [12].

The probability study made by Dowding [13] revealed that no cosmetic or threshold cracking takes place below a particle velocity of $12 \mathrm{~mm} / \mathrm{s}$. The data considered by him for the study included the low frequencies of below $4 \mathrm{~Hz}$ collected by Dvorak [14]. Residential structures typically resonate at frequencies in the range of $3 \mathrm{~Hz}$ to $8 \mathrm{~Hz}$ indicating a problem. However, the above study indicated no danger even upto $12 \mathrm{~mm} / \mathrm{s}$ PPV with such low frequencies. To substantiate this Siskind et al. [15] conducted studies and observed no blast-induced cracking upto $19 \mathrm{~mm} / \mathrm{s}$ PPV. The probabilistic data provided above may not be valid in specific cases as total time history of vibration event is more important for response spectrum of the structure. The damage that results from vibration will depend on the nature of source, transmission characteristics of the intervening medium/strata, inherent strength of the subject structure, height and rigidity of the structure and foundation design etc. Damage caused by ground vibration is dependent on the amplitude of the ground velocity and on the frequency of the ground motion. All the vibration standards till date are based on the resultant peak particle velocity of ground vibration because this is accepted as the best criterion for assessing levels of vibration damage. The recent trend is to refer to the frequency of the ground motion also. Low frequency waves cause more damage to structure particularly in case of multi-storied buildings. Different countries adopt different standards of safe limits of vibration in terms of peak particle velocity (PPV) for various types of structures. In India DGMS suggested standards of blast vibrations vide their circular No.7 of [16] are being implemented. Accordingly, the permissible peak particle velocity (PPV) at the foundation level of structures in mining area is detailed in Table 1.

Table 1: Permissible Peak Particle Velocity as per DGMS in India [16].

\begin{tabular}{|c|c|c|c|}
\hline \multirow{2}{*}{ Type of Structure } & \multicolumn{3}{|c|}{ Dominant frequency, $\mathrm{Hz}$} \\
\hline & $<8 \mathrm{~Hz}$ & $8-25 \mathrm{~Hz}$ & $>25 \mathrm{~Hz}$ \\
\hline \multicolumn{4}{|c|}{ (A) Buildings/structures not belonging to the owner } \\
\hline Domestic houses/structures (Kuchha brick and cement) & 5 & 10 & 15 \\
\hline Industrial Buildings RCC and framed structures) & 10 & 20 & 25 \\
\hline Objects of historical importance and sensitive structures & 2 & 5 & 10 \\
\hline \multicolumn{4}{|c|}{ (B) Buildings belonging to owner with limited span of life } \\
\hline Domestic houses/structures (Kuchha brick and cement) & 10 & 15 & 25 \\
\hline Industrial buildings (RCC \& framed structures) & 15 & 25 & 50 \\
\hline
\end{tabular}

\section{Objective}

The objective of the study was to suggest the maximum explodable charge per delay (MCPD) and per round for limiting the
Peak Particle Velocity (PPV) of ground vibration within permissible limits for NONEL system of blasting with emulsion explosives considering the existing surface structures in the vicinity of the mine.

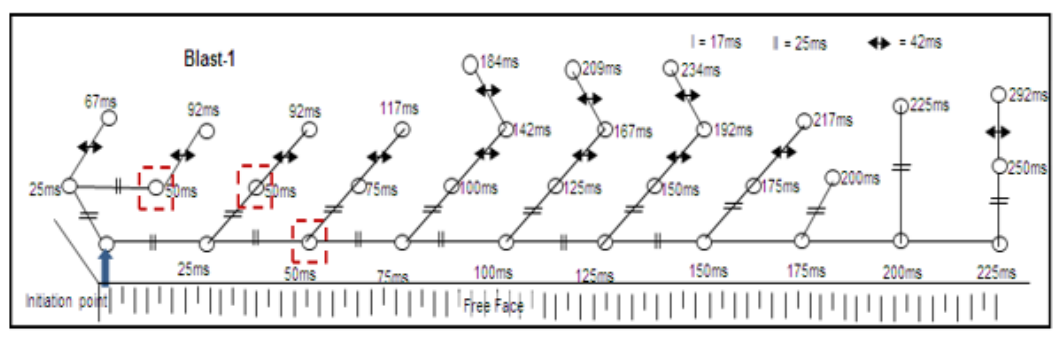

Suggested firing pattern

$\|=25 \mathrm{~ms} \leftrightarrow=42 \mathrm{~ms}$

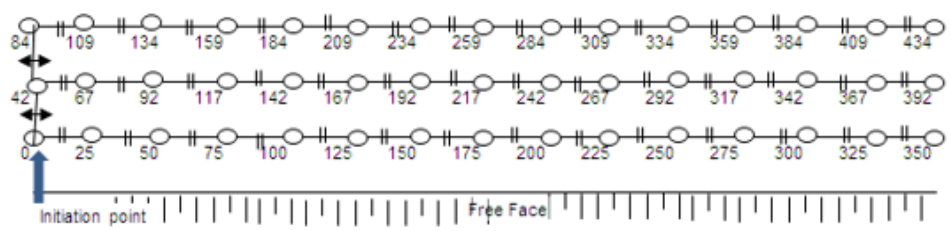

Figure 1: Details of Tie-ins and Initiation Arrangement. 


\section{Case Description}

To meet the stated objectives, a field study was conducted on sandstone overburden formation of an opencast coal mine of BCCL, a subsidiary of Coal India Ltd. (CIL). The mine is being worked by mechanized drilling and deep hole blasting method. Crawler mounted DTH pneumatic drill of $150 \mathrm{~mm}$ diameter is being used to drill blast holes. The holes are made near vertical. Staggered pattern of drilling is to be followed for optimum distribution of explosive energy. However, pattern of drilling was found to be not very consistent on a few occasions leading to improper burden relief affecting fragmentation and causing boulder generation. Lack of proper bench face is also seen on a couple of occasions due to new opening of benches. The strata are also found to be disturbed due the presence of old depillared/caved workings. Numerous free faces caused low vibrations levels and improper fragmentation due to loss of explosive energy. This needs a special attention of mine management for realizing the fruits of good blast design. All the 11 trial blasts utilized Nonel system of initiation with trunk line delays of $17 / 25 \mathrm{~ms}$ between the holes in a row and 25/42ms between the rows. Down the hole initiation systems of $250 / 300 \mathrm{~ms}$ (of varying length depending on hole depth) were used with deck charging. Details of tie-ins and initiation arrangement are given in Figure 1 and according to figure the MCPD of suggested firing pattern having quantity of individual blast hole as compare to another pattern.

Depth of blast holes, in various round of blasts, in general, varied from 6 to $7 \mathrm{~m}$. The effective burden varied from 2.5 to $3.0 \mathrm{~m}$ and spacing varied from 3.0 to $3.5 \mathrm{~m}$. The charge per round varied from $400 \mathrm{~kg}$ to $2115 \mathrm{~kg}$ and the maximum charge per delay varied from $30 \mathrm{~kg}$ to $130 \mathrm{~kg}$. Blasting was carried out using cartridge explosives and site mixed emulsions (SME) explosives and cartridge booster Explosives. It was found that powder factor varied between $1.0-2.2 \mathrm{~m}^{3} / \mathrm{kg}$ of explosive depending on formation (compact /cracked), type of initiation sequence and other blast design variations.

\section{Methodology}

To meet the above stated objective field reconnaissance was done to identify the different formations and fragile locations such as benches facing human habitat and nearby the villages. During the study 11 trial blasts with non-electric delay (NONEL) were conducted and ground vibration and air overpressure were monitored (Figure 2) with the help of Minimate/ Minimate plus seismographs. A total of 19 events were recorded by these seismographs at various blast monitoring stations nearest to the blast site as shown in Table $2 \& 3$.

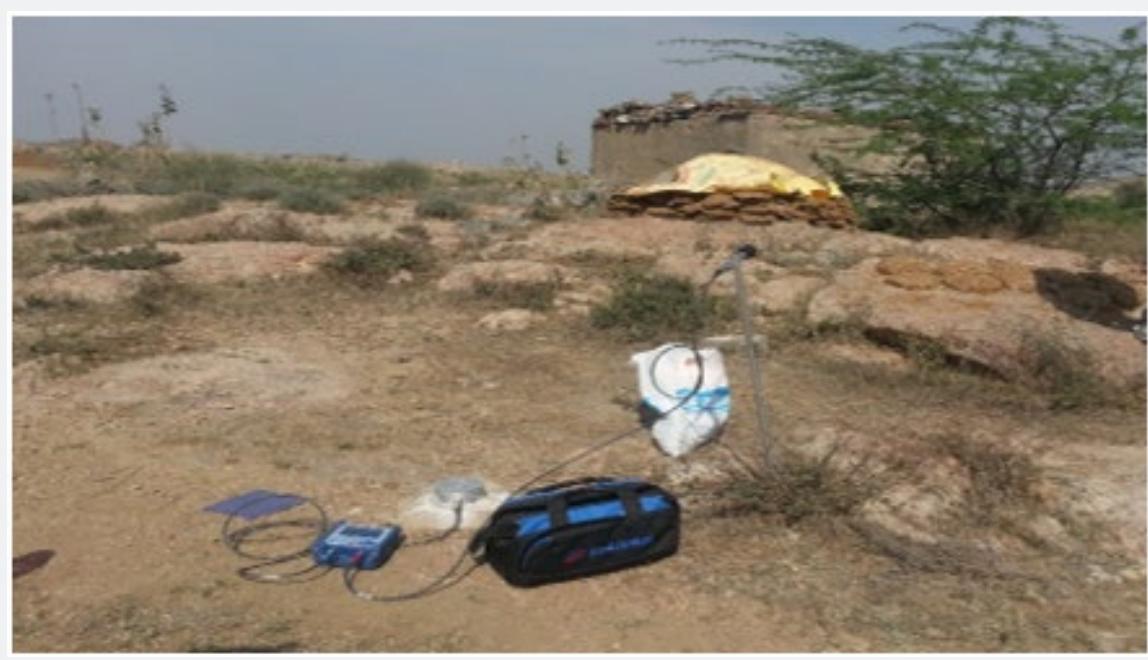

Figure 2: PPV and Air Overpressure Measuring Station.

Table 2: Trial Blast Details.

\begin{tabular}{|c|c|c|c|c|c|c|c|c|}
\hline $\begin{array}{c}\text { Blast } \\
\text { No. }\end{array}$ & $\begin{array}{c}\text { Burden, } \\
\text { (m) }\end{array}$ & $\begin{array}{l}\text { Spacing } \\
\text { (m) }\end{array}$ & No. of Holes & $\begin{array}{c}\text { Total Charge } \\
\text { (TW) } \\
\text { (Kg) }\end{array}$ & $\begin{array}{l}\text { Avg. Charge per hole, } \\
\text { (kg) }\end{array}$ & $\begin{array}{l}\text { Max. Charge per } \\
\text { delay, (kg) }\end{array}$ & $\begin{array}{c}\text { Powder Factor, } \\
\left(\mathrm{m}^{3} / \mathrm{kg}\right)\end{array}$ & Remarks \\
\hline 1 & 3 & 3.5 & 33 & 1375 & $40-45$ & 93.75 & 1.51 & $\begin{array}{c}\text { Two decks } \\
(12.5+31.25)\end{array}$ \\
\hline 2 & 3 & 3.5 & 23 & 925 & $40-41$ & 82 & 1.57 & ------- \\
\hline 3 & 3 & 3.5 & 9 & 400 & $44-45$ & 45 & 1.42 & ------ \\
\hline 4 & 3 & 4 & 12 & 467 & 38-39 & 39 & 1.85 & ------- \\
\hline 5 & 3 & 4 & 34 & 2115 & $62-63$ & 126 & 1.16 & ------ \\
\hline 6 & 3 & 4 & 15 & 583.34 & $38-39$ & 31.5 & 1.85 & Two decks \\
\hline
\end{tabular}




\section{Insights in Mining Science \& Technology}

\begin{tabular}{|c|c|c|c|c|c|c|c|c|}
\hline 7 & 3 & 3.5 & 12 & 700 & $55-60$ & 60 & 1.08 \\
\hline 8 & 3 & 3.5 & 15 & 425 & $25-30$ & 30 & 2.22 \\
\hline 9 & 3 & 3.5 & 16 & 750 & $45-47$ & 63 & 1.34 \\
\hline 10 & 3 & 3.5 & 22 & 1400 & $55-65$ & 130 & Two decks \\
\hline 11 & 3 & 3.5 & 9 & 500 & $50-60$ & 60 & -1.99 \\
\hline
\end{tabular}

\section{Analysis and Discussions}

The analysis of ground vibration records as presented in Table 4 reveals that the dominant frequencies of the ground vibration in the mine varied from 3.5 to $32.5 \mathrm{~Hz}$. It may be noted that most of the frequencies were ranging between $8-25 \mathrm{~Hz}$ (74 \%). Consid- ering the surface structures (brick houses on cement belonging to owner) as the critical structure to be protected, the maximum allowable Peak Particle Velocity (PPV) is fixed at $15 \mathrm{~mm} / \mathrm{s}$ based on the trial blasts and the ground vibration monitoring near structures during blasting (refer to Table 1 on DGMS guidelines).

Table 3: Field instrumental Recorded Details and Analysis Data.

\begin{tabular}{|c|c|c|c|c|c|c|c|c|c|c|}
\hline S.No./Blast No. & $\begin{array}{l}\text { H Distance } \\
\text { (m) }\end{array}$ & $\begin{array}{l}\text { V Distance } \\
\text { (m) }\end{array}$ & $\begin{array}{l}\text { R Distance } \\
\text { (m) }\end{array}$ & PVS (mm/s) & $\begin{array}{c}\text { Dominant frequency } \\
(T, V, L)\end{array}$ & $\begin{array}{l}\text { AOP } \\
\text { (dbl) }\end{array}$ & $\begin{array}{c}\text { Scale Distance (SD) } \\
\left(R / W^{\wedge} 1 / 2\right)\end{array}$ & $\begin{array}{l}\text { Log } \\
\text { SD }\end{array}$ & $\begin{array}{l}\text { SD } \\
\text { TW }\end{array}$ & $\begin{array}{l}\log S D \\
\text { TW }\end{array}$ \\
\hline $01 / 01$ & 341.69 & 7.5 & 341.77 & 1.75 & $12,17,12$ & 88 & 35.3 & 1.548 & 9.22 & 0.96 \\
\hline $02 / 02$ & 416.93 & 2.74 & 416.94 & 1.97 & $14,14,12,5$ & 88 & 46.04 & 1.663 & 13.71 & 1.14 \\
\hline $03 / 03$ & 210.49 & 1.49 & 210.49 & 1.57 & $10.5,17,18$ & 119.1 & 31.38 & 1.497 & 10.52 & 1.02 \\
\hline $04 / 04$ & 271.5 & -2.49 & 271.51 & 1.79 & $8,12.5,8.5$ & 109.5 & 43.48 & 1.638 & 12.56 & 1.1 \\
\hline $05 / 05$ & 291.85 & -4.57 & 291.89 & 8.21 & $8.5,7.5,8.5$ & 122.9 & 26 & 1.415 & 6.35 & 0.8 \\
\hline $06 / 06$ & 224.32 & 3.6 & 224.35 & 1.75 & $7.5,17.5,9$ & 129.9 & 39.97 & 1.602 & 9.29 & 0.97 \\
\hline $07 / 06$ & 292.33 & 2.6 & 292.34 & 3.95 & $9.5,16.5,9$ & 128 & 52.09 & 1.717 & 12.1 & 1.08 \\
\hline $09 / 07$ & 302.94 & -0.5 & 302.94 & 6.27 & $10,16,8.5$ & 88 & 39.11 & 1.592 & 11.45 & 1.06 \\
\hline $10 / 08$ & 204.52 & -3.48 & 204.55 & 1.77 & $6,6,5.5$ & 117.9 & 37.35 & 1.572 & 9.92 & 1 \\
\hline $11 / 08$ & 363.25 & -3.57 & 363.27 & 1.29 & $6,6,6$ & 115.6 & 66.32 & 1.822 & 17.62 & 1.25 \\
\hline $12 / 08$ & 315.44 & -3.57 & 315.46 & 1.53 & $9,5.5,6$ & 88 & 57.6 & 1.76 & 15.3 & 1.18 \\
\hline $14 / 10$ & 128.85 & 2.91 & 128.88 & 17.6 & $23,32.5,23$ & 120.4 & 11.3 & 1.053 & 3.44 & 0.54 \\
\hline $15 / 10$ & 296.25 & 2.82 & 296.26 & 7.19 & $3.5,5,10.5$ & 120 & 25.98 & 1.415 & 7.92 & 0.9 \\
\hline $16 / 10$ & 242.92 & 2.82 & 242.94 & 8.29 & $9,10,9.5$ & 88 & 21.31 & 1.329 & 6.49 & 0.81 \\
\hline $17 / 11$ & 175.45 & 0 & 175.45 & 4.21 & $13,16,11$ & 123.5 & 22.65 & 1.355 & 7.85 & 0.89 \\
\hline $19 / 11$ & 241.67 & 0.95 & 241.67 & 3.67 & $9,16,10.5$ & 88 & 31.2 & 1.494 & 10.81 & 1.03 \\
\hline
\end{tabular}

Table 4: Analysis of Blasting Events.

\begin{tabular}{|c|c|c|c|c|}
\hline Parameters & Range & Class Interval & No. of Events & Remarks \\
\hline \multirow{3}{*}{ W, Max. charge per delay (kg) } & \multirow{3}{*}{$30-130$} & $<50$ & 7 & \multirow{3}{*}{$\begin{array}{l}\text { Majority of the events utilized less than } 100 \mathrm{~kg} \text { of explo- } \\
\text { sive per delay }\end{array}$} \\
\hline & & $50-100$ & 8 & \\
\hline & & $>100$ & 4 & \\
\hline \multirow{3}{*}{$\begin{array}{l}\text { PPV, Peak Particle Velocity (peak vector sum) } \\
\text { mm/s }\end{array}$} & \multirow{3}{*}{$\begin{array}{c}1.29- \\
17.6\end{array}$} & 5 or below & 12 & \multirow{3}{*}{$\begin{array}{c}\text { Most of the events (17 out of 19) have shown a PPV less } \\
\text { than } 10 \mathrm{~mm} / \mathrm{s}\end{array}$} \\
\hline & & $5-10$ & 5 & \\
\hline & & $>10$ & 2 & \\
\hline \multirow{4}{*}{ Time of occurrence of Peak vector sum (PVS) (ms) } & \multirow{4}{*}{$2-600$} & $<100$ & 6 & \multirow{4}{*}{$\begin{array}{c}\text { Majority of events (14) recorded PVS within a duration } \\
\text { of } 200 \mathrm{~ms}\end{array}$} \\
\hline & & $100-200$ & 8 & \\
\hline & & $200-300$ & 4 & \\
\hline & & $>300$ & 1 & \\
\hline Radial distance, $\mathrm{R}(\mathrm{m})$ & $129-417$ & \multicolumn{2}{|c|}{ Blast site to monitoring station } & Structures belong to owner \\
\hline \multirow{3}{*}{ Dominant frequency $(\mathrm{Hz})$} & \multicolumn{3}{|c|}{ Transverse, Vertical, and Longitudinal } & \multirow{3}{*}{$\begin{array}{l}74 \% \text { events recorded more than } 8 \mathrm{~Hz} \text { dominant frequen- } \\
\text { cy. This has a bearing on fixing allowable PPV }\end{array}$} \\
\hline & $<8$ & $8-25$ & $>25$ & \\
\hline & 15 & 39 & 3 & \\
\hline
\end{tabular}




\section{Insights in Mining Science \& Technology}

AOP (Air over pressure), dBL

$88-130$

Majority of the events are well below the safe limits of $120 \mathrm{dBL}$

\section{Ground Vibration Predictor}

Applying the method of least square regression analysis, an empirical equation is established relating resultant peak particle velocity, $\mathrm{V}(\mathrm{mm} / \mathrm{sec})$ of the ground, the distance of blasting site from the point of monitoring, $\mathrm{R}(\mathrm{m})$ and the maximum charge per delay, W (kg) (Figure 3). The derived empirical ground vibration predictor equation for the mine with Non-electric (NONEL) initiation system is given below (Eq. 1):

$V=891 *\left(\frac{R}{\sqrt{W}}\right)^{-1.44}$ (at 95\% confidence interval) (Eq.1)

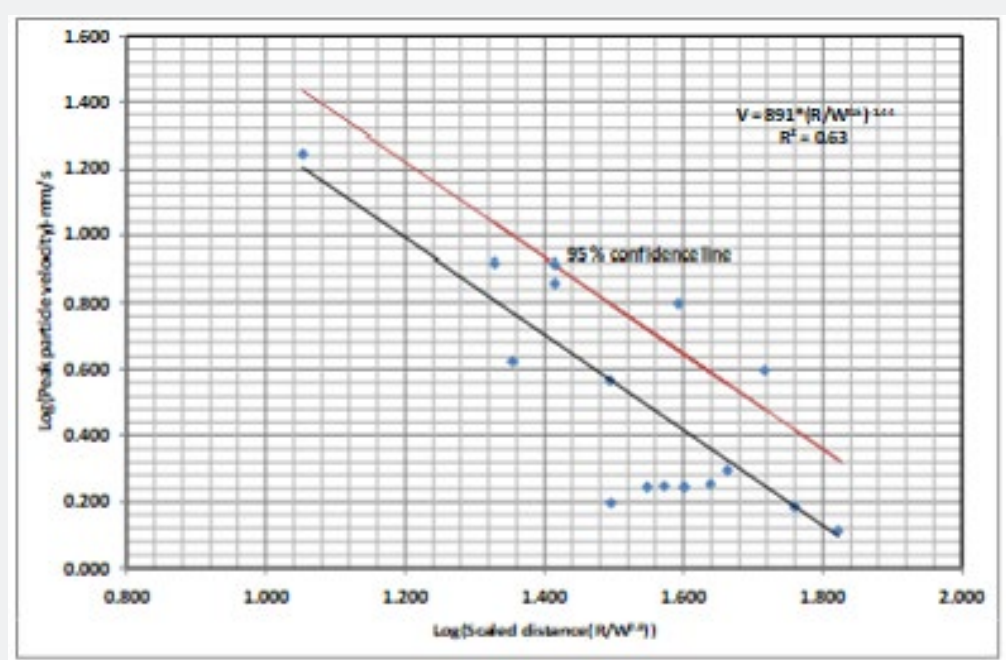

Figure 3: Ground Vibration Predictor for Maximum Charge per Delay, for the Mine.

Coefficient of determination $\left(\mathrm{R}^{2}\right)=0.63$

Equation 2 depicts the relation among resultant peak particle velocity, $\mathrm{V}(\mathrm{mm} / \mathrm{sec})$ of the ground, the distance of blasting site from the point of monitoring, $\mathrm{R}(\mathrm{m})$ and the total charge per round, TW (kg) (Figure 4).

$V=200 *\left(\frac{R}{\sqrt{T W}}\right)^{-1.62}$ (at 95\% confidence interval) (Eq.2)

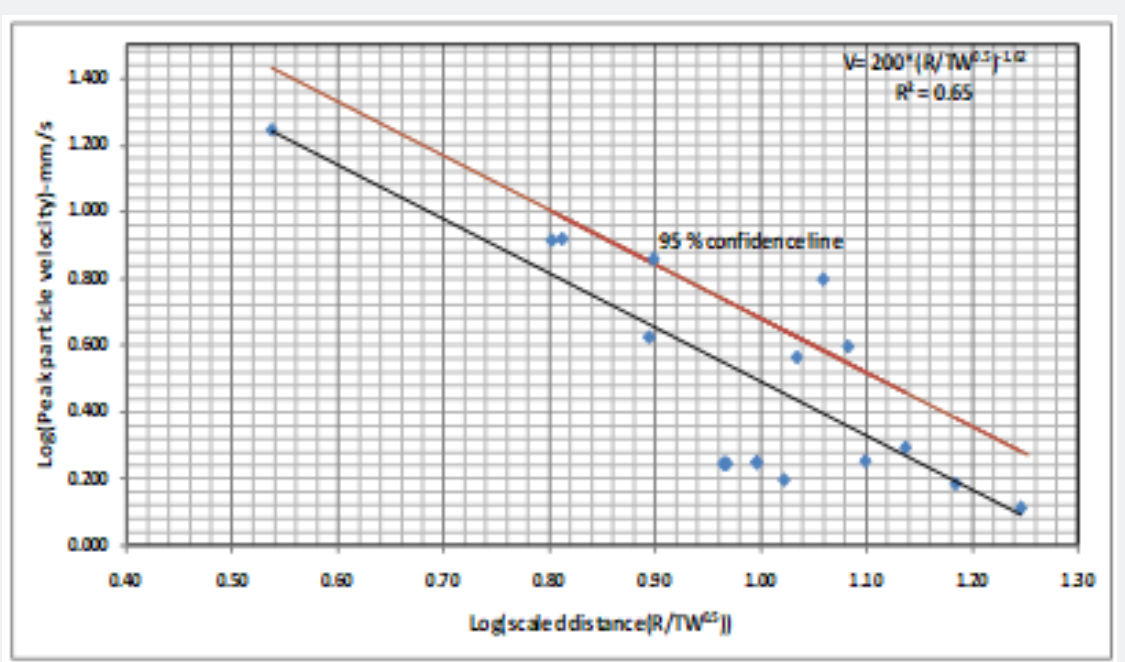

Figure 4: Ground Vibration Predictor for Total Charge (TW) per Round, for the Mine.

Coefficient of determination $\left(\mathrm{R}^{2}\right)=0.65$

The scaled distance and peak particle velocity values are plotted on a log-log scale. Statistically, the above equations have reasonable index of determination and therefore can be accepted for prediction of ground vibration and estimation of safe maximum charge per delay and per round for various distances of structures from the blasting sites. The suggested maximum charge per delay using Nonel initiating systems (TLD \& DTH) for the safety of surface structures is given in Table 5. 
Table 5: Suggested Explosive Charge per Delay and per Round (kg).

\begin{tabular}{|c|c|c|c|c|}
\hline \multirow[b]{2}{*}{ Distance $(\mathrm{m})$} & \multicolumn{2}{|c|}{ Maximum Charge per Delay W (kg) } & \multicolumn{2}{|c|}{ Total Charge per Round TW (kg) } \\
\hline & $\begin{array}{c}\text { Kuchha brick and cement houses } \\
\text { belonging to owner (PPV-15 mm/s) }\end{array}$ & $\begin{array}{l}\text { RCC structures not belonging } \\
\text { to owner (PPV-20 mm/s) }\end{array}$ & $\begin{array}{l}\text { Kuchha brick and cement houses } \\
\text { belonging to owner (PPV-15 mm/s) }\end{array}$ & $\begin{array}{l}\text { RCC structures not belonging to } \\
\text { owner (PPV- } 20 \mathrm{~mm} / \mathrm{s} \text { ) }\end{array}$ \\
\hline 10 & 0.34 & 0.51 & 4.08 & 5.83 \\
\hline 20 & 1.38 & 2.05 & 16.34 & 23.31 \\
\hline 30 & 3.09 & 4.62 & 36.76 & 52.44 \\
\hline 50 & 8.6 & 12.82 & 102.12 & 145.67 \\
\hline 75 & 19.34 & 28.84 & 229.78 & 327.76 \\
\hline 100 & 34.39 & 51.28 & 408.49 & 582.68 \\
\hline 125 & 53.73 & 80.12 & 638.27 & 910.44 \\
\hline 150 & 77.37 & 115.38 & 919.11 & 1311.04 \\
\hline 200 & 137.55 & 205.11 & 1633.98 & 2330.73 \\
\hline 300 & 309.49 & 461.5 & 3676.45 & 5244.14 \\
\hline 400 & 550.21 & 820.45 & 6535.92 & 9322.92 \\
\hline 500 & 859.7 & 1281.96 & 10212.37 & 14567.07 \\
\hline
\end{tabular}

\section{Air Overpressure Monitoring}

During trial blasts air overpressure (air blast) was also monitored and the details of measurements are given in Table $3 \& 4$. The values obtained were analyzed for a propagation equation and the same has been shown in Figure 5. All the observations were well within safe permissible limits.

$A O P=158 *\left(\frac{R}{\sqrt[3]{W}}\right)^{-0.07}$ (Eq.3)

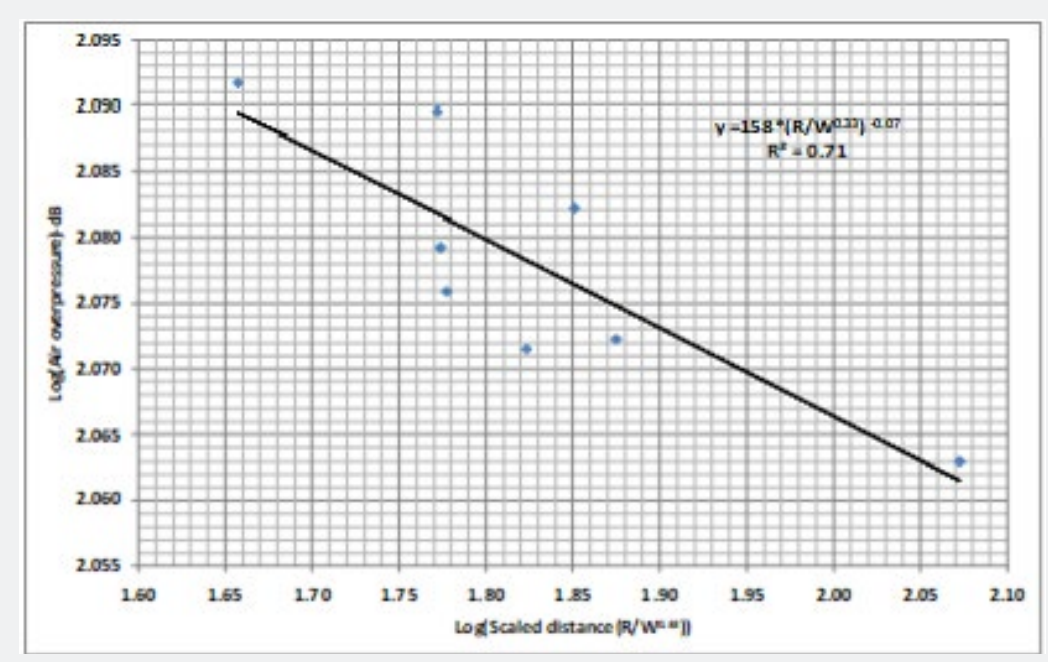

Figure 5: Air Overpressure Predictor Equation, for the Mine.

Coefficient of determination $\left(\mathrm{R}^{2}\right)=0.71$

A good index of determination has been obtained by eliminating judiciously the offsets which are because of wind speed, RL difference, lack of bench face etc.

\section{Conclusion}

This paper presents the scientific investigations on the assessment of ground vibration and air overpressure while blasting in the mine. During the investigation period 11 rounds of blasts comprising a total of 19 events were recorded. Based on the analysis of data following conclusions may be drawn: a) The site-specific empirical equation relating vibration, distance and maximum explosive quantity per delay for the overburden rock is

$V=891 *\left(\frac{R}{\sqrt{W}}\right)^{-1.44}$

Coefficient of determination (R2) $=0.63$

The dominant frequencies of ground vibration in the 11 rounds of blasts recorded varied from $3.5 \mathrm{~Hz}$ to $32.5 \mathrm{~Hz}$. However, most events $(74 \%)$ recorded dominant frequency with more than $8 \mathrm{~Hz}$.

b) Assuming a safe level of ground vibration as $15 \mathrm{~mm} / \mathrm{sec}$ for safety of surface structures (kuchha brick houses with ce- 
ment) near the mine belonging to owner and $20 \mathrm{~mm} / \mathrm{sec}$ for concrete structure not belonging to owner, the maximum permissible charge per delay is calculated using site specific empirical equations for various distances of surface structures from the blast site and the results are given in Table 5.

c) The AOP is in the safe limit and maximum percentage of noise is below $120 \mathrm{db}$ which causes minor harm to the habitats.

\section{Acknowledgement}

The authors express their gratitude towards the staff and management of BCCL, a subsidiary of Coal India Ltd. for granting permission to conduct the study.

\section{References}

1. Singh PK, Roy MP, Paswan RK, Dubey RK, Drebenstedt C (2015) Blast vibration effects in an underground mine caused by open-pit mining. International Journal of Rock Mechanics and Mining Sciences 80: 7988.

2. Tripathy GR, Shirke RR, Kudale MD (2016) Safety of engineered structures against blast vibrations: A case study. Journal of Rock Mechanics and Geotechnical Engineering 8(2): 248-255.

3. Venkatesh HS, Theresraj AI, Balachander R, Gupta RN (2005) Near field vibration monitoring for rock mass damage control. The Journal of explosives Engineering USA July issue.

4. Wiss JF, Linehan PW (1978) Control of vibration and blast noise from surface coal mining. USBM OFR 103-179.

5. Monjezi M, Ahmadi M, Sheikhan M, Bahrami A, Salimi AR (2010) Predicting blast-induced ground vibration using various types of neural networks. Soil Dynamics and Earthquake Engineering 30: 1233-1236.
6. Nicholls HR, Johnson CF, Duvall WI (1971) Blasting Vibrations and their Effects on Structures. U.S. Bureau of Mines R.I. 656 pp. 105.

7. Chiapetta RF, Postupack C (1995) An update on causes and recommendations for controlling coal damage when blasting overburden Procs. Explo-95 Brisbane: 345-360.

8. Hagan TN (1983) The influence of controllable blast parameters on fragmentation and mining costs, Procs. $1^{\text {st }}$ Int. Symp. On Rock Fragmentation by Blasting, Lulea Sweden pp: 31-51.

9. Rai P (2002) Evaluation of effect of some blast design parameters on fragmentation in opencast mine. Ph.D. thesis Banaras Hindu University, Varanasi.

10. Wei Wo (1984) The effect of simulated detonator scatter on rock fragmentation and ground vibrations in single row bench blasting. MS Thesis Univ. of Missouri, Rolla.

11. Agrawal H, Mishra AK (2018) Probabilistic analysis on scattering effect of initiation systems and concept of modified charge per delay for prediction of blast induced ground vibrations. Measurement 130: 306-317.

12. Aldas GGU, Ecevitoglu B (2008) Waveform analysis in mitigation of blast-induced vibrations. Journal of Applied Geophysics 66(1-2): 2530.

13. Dowding CH (1985) Blast vibration monitoring and control.

14. Dvorak A (1962) Seismic effects of blasting on brick houses, Prace Geofyrikenina Ustance, Ceskoslovenski Akademic, ved. No.159 Geogysikalni, Sbornik.

15. Siskind DE, Stagg MS, Kopp JW, Dowding CH (1980) Structure response and damage produced by ground vibrations from surface blasting RI 8507. US Bureau of Mines, Washington, DC.

16. (1997) DGMS Circulars (Tech.).
This work is licensed under Creative Commons Attribution 4.0 License DOI: 10.19080/IMST.2019.01.555557 